\title{
Necessity of Tutor Training in Architecture Education Using Rasch Measurement Model
}

\author{
${ }^{1}$ BadiossadatHassanpour, ${ }^{1}$ Nangkula Utaberta and ${ }^{2}$ Azami Zaharim \\ ${ }^{1}$ Department of Architecture, Faculty of Engineering and Built Environment, \\ National University of Malaysia (UKM), 43600 Bangi, Malaysia \\ ${ }^{2}$ Centre for Engineering Education Research, \\ Universiti Kebangsaan Malaysia, 43600 UKM Bangi, Selangor, Malaysia
}

Received 2012-05-30, Revised 2012-09-12; Accepted 2012-09-12

\begin{abstract}
This is an unwritten norm that says learning can take place in the job. But learning in tutors' position in the meaning of gaining experience is good but in case of try and error would be crucial. On the other hand there is a belief among practitioners that they assume that who has some experience in architecture is fully equipped for teaching. Since education of art and architecture are sophisticated and they are completely based on tutor and students, tutors and instructors should fully prepare for this position. There are many holistic problems statements and suggestions, but there were no measurement tool to monitor this problem and some executive suggestions. This research for the first time used Rasch momeasurment model and Mini Facet sofware to evaluate tutors' performance in architecture school. As case study second year design studio of Universiti Kebangsaan Malaysia and final submission have chosen which 4 tutur were part of evaluation. The modeling demonstrates this claim that young tutors with less experience and part time academics needs to be have some formal training to gain experience. Graduations from architecture degree or having practical experiences separately are not enough to make one a studio masters. This study also will present some recommendations on some learning workshops and supportive workshops to prepare creative architecture tutors.
\end{abstract}

Keywords: Architecture Education, Tutor Training, Rasch Measurement

\section{INTRODUCTION}

Architecture is a multidisciplinary field of study that draws on the arts, science and social sciences. There are five areas of study in the UK architecture syllabus (part 1 and part 2) as well as a practical training requirement (Royal Institute of British Architects and Architects Registration Board 1997). The five areas are: architectural design, the cultural context of architecture; environmental design; constructional and architectural technologies; communication skills; professional studies and management. However, the most important part of architectural education in terms of curriculum focus and time spent by students is architectural design. It is in the design studio that students are expected to bring together knowledge from the different disciplines to inform the development of their architectural designs.

The design studio offers the potential to provide a multifaceted and enriching learning experience. One inherent educational strength in studio teaching is the implicit commitment to 'experiential learning 'or learning by doing. Schon (1985), in his work educating the reflective practitioner, describes design studio teaching in architecture as a 'practicum'- a setting designed for the task of learning a practice. In a context that approximates a practice world, students learn by doing, by undertaking projects that simulate and simplify practice. Schon calls this a 'virtual world', relatively free of pressures, distractions and risks of real world.

The crit or project review is a form of teaching to which schools of architecture have subscribed for decades and this historical continuity would seem to suggest that in the past it has been a successful mode of transmitting the knowledge and skills of the architect to the next generation of the profession. But continuity of a social institution may reflect more than functional effectiveness. It can also reflect broader social processes such as the exercise of power and influence. Thus, for example, the review is an established mode of teaching, National University of Malaysia (UKM), 43600 Bangi, Malaysia 
whereby students learn from tutors' comments on their own and their peers' work.

While much has been written about the education of architects (Boyer and Mitgang, 1996; Pearce and Toy, 1995; Schon, 1985; 1990), relatively little has been said about the preparation of teachers of architecture. No doubt this is in part a reflection of the lack of training for lecturers in higher education generally, which has been the norm until recently. As Rhowbotham (1995) has remarked: It is customary among practicing architects to assume that those who have achieved some degree of experience are automatically equipped with all that is necessary to teach.

Higher education in general and schools of architecture in particular have witnessed considerable change over decades. Most have increased their student intake and reduced the number of tutors and are trying to retain the same academic standards in a much shorter academic year.

Modularization has led to further fragmentation of integrated subjects such as architecture. It has also required teaching to become much more quantifiable and emphasis learning processes rather than teaching input. Teachers are expected to reduce students contact time in order to maintain a cost effective staff-student regime. This climate of change in higher education has produced particular difficulties for design courses such as architecture. A strong design ethic persists, involving problem solving design exercise. The studio culture is seen as sacrosanct and central to learning by the act of practicing design buildings. Traditionally this has involved one to one tuition, which many schools can now ill afford. The design focus is self absorbing and time consuming and its evaluation involves assessing the designed artifact rather than the student's academic progress.

Most teachers in schools of architecture have not received formal teacher training. They generally come straight from practice and tend to replicate their own student experience whist learning on the job and therefore tend to lack understanding of the theory of educational processes; this makes it difficult for them to be objective about defining explicit teaching and learning outcomes within the holistic teaching environment.

The tutors have the explicit responsibility of advancing the art of architecture in their own way, as well as developing the potential of each student for whom they are responsible. Thus they must have an architectural agenda as well as an educational one.

Yet none of them is trained as a teacher, they could perhaps have relied on memories of their own education than can called hit-and-miss the tutoring. Mumford describes negative capability in the learning process is the ability to allow people to learn on the job from their mistakes in both academic environment and the work place.
In spite of all claims there is no study based on real documentation and evidence. In fact there were not adequate systems to demonstrate the problem and be the base for improvement or suggestions. The main target of this study is to monitor and evaluate tutor's performance in jury sessions, as the key member of design studio and assessment sessions and to show the necessity of preparation for volunteers of joining to academic as in part time or full time tutors. So in the first phase this study will explain about the tutor role in design studio then by introducing universiti Kebangsaan Malaysia and second year design studio as case study and Rasch measurement model and mini facet software will analyze the tutor's performance. Finally based on results, some recommendations will be given.

\subsection{The Role of Tutor in Architecture Education}

The aim in educating architects is seen as developing the imaginative, conceptual and practical skills necessary for students to identify human needs and aspirations and to be able to meet or express these in space and form (Brown and Yates, 2002). Donald Schon asserts that these defining of abilities can be called 'thinking like an architect'. It would be students' capacity to see unfamiliar situations as familiar ones and bring their past experience to bear on the unique case. The design tutor is to develop these abilities.

It should be part of students' capacity to see-as and do-as that allows us to have a feel for problems that do not fit existing rules. Moreover, each new experience of reflection- in action enriches his repertoire.

Seeing-as is not enough, however. When a practitioner sees a new situation as some element of his repertoire, he gets a new way of seeing it and a new possibility for action in it, but the adequacy and utility of his new view must still be discovered in action. Reflection in action necessarily involves experiment. Students would be expected to acquire the material by reading, listening and watching, familiarizing themselves with examples of practice problems matched to appropriate categories of theory and technique. Coaching would consist in observing student performance, detecting errors of application, pointing our correct responses (Donald Schon).

It is in the nature of the studio principle for the tutor to be exploring unknown territory with the students for whom he is responsible (O'Reilly et al., 1999).

Much of the knowledge and skill inherent in good design tutoring remains tacit, in the sense identified generally by Polanyi (1967) and delineated in the design studio by Schon (1985). Moreover, much of the actual practice of design teaching takes place in the relative privacy of the design studio. Many aspects of design teaching thus remain barely articulated. 
Assessment and grading of students' projects is another role of tutors and academics. In any discussion about the jury in architectural education we quickly find how slippery the object of scrutiny is.

As Crooks et al. (1996) notes, assessment guides students' judgment of what is important to learn, affects their motivation and self-perceptions of competence, structures their approaches to and timing of personal study and affects the development of enduring learning strategies and skills'.

There are different assessment method and grading models that designed and implemented by pioneer universities in architecture education and followed by other universities around the world. Step by step by improving the definition of education and assessment these models have improved and changed. One of these systems is comparative method. In this appraisal model the student's projects will compare with each other. In fact jurors or the related tutors that are going to give marks in submission day, judge the quality of projects holistically then they rank the projects. Grades follow in descending form best project to worth one. Comparing students with each other is unfair, because students are from different backgrounds and talents. Students deserve to be graded on the basis of the quality of their work alone, uncontaminated by reference to how other students in the studio perform on the same or equivalent tasks and without regard to each student's previous level of performance (Sadler, 2005).

In comparative system, the holistically attitude to the projects judgment leads to neglect Student's Creativity and abilities in some contexts. Students can't be aware of their weak and strong points and by this way and they can't do any effort to increase their marks and just lucky students who are skillful in graphic design are able to impact jurors for better grades. On the other hand making pair-wise comparisons just among small set of students submissions is possible. It will be very difficult in large amount of projects and students. In recent years, universities have made explicit overtures towards criteriabased grading and reporting. Under these models, grades are required to evaluate student's achievement in fulfilling juror's expectations. These expectations can be explain in different form. We name these expectations as course objectives. The objectives are assumed to provide the basis for the criteria, but exactly what the criteria are is in essence left undefined (Sadler, 2005). These objectives should be known by instructors, students and especially external jurors. Because invited jurors have their certain tendency and assumed objectives that would be the base of their grading. This incoherency may lead to variant in given marks by different instructors and students dissatisfaction.

\section{MATERIALS AND METHODS}

\subsection{Case Study and Research Model}

According to (Mahmood, 2008), academic excellence is student's achievements which are based on university's assessments such as test, assignment, presentation, final exam. Assessment should reflect these understandings by employing a diverse array of methods, including those that call for actual performance, using them over time so as to reveal change, growth and increasing degrees of integration. Such an approach aims for a more complete and accurate picture of learning and therefore firmer bases for improving our students' educational experience (Astin, 1992).

To monitor and evaluate how the tutors 'performance and their consistency is in jury sessions, architecture department of Universiti Kebangsaan Malaysia and second year design studio has chosen as case study. The reason to choose second year architecture students is that in this step they are not expert enough in managing their project base on critique and receiving and giving comments. In this step they are trying to make experiences by iterating their design process under supervision of their studio masters. First and third year students perceive the review as a sound forum for promoting and learning about the client and user issues, though second year students tended to become more skeptical and tutor role would be more crucial relatively.

Final submission of the third project which was designing a medium size building in a dense urban context has chosen. 23 students were presented their designed projects to the jurors. The students were using Auto cad and Archi Cad to present their design. Before the submission day students have been informed about the objectives of the projects and assessment tasks which are going to be assessed by jurors. Also an evaluation sheet has been prepared for all the jurors that were containing the objectives and criteria for the assessment.

The defined evaluation sheet for this submission day was included 3 main criteria which were included oral and graphic presentation, design development and model.

Each of these has defined into different tasks for marking. The tasks are as below:

- Oral and graphic presentation:

- Attire and composition

- How clear is the information

- Focus and explanation

- Design development:

- Study on architectural language and understanding of the issue

- Understanding of the precedent study

- Concept and idea development 
- Design approaches

- Respond to the site

- $\quad$ Spaces and spatial integration

- Completeness of drawings (sketches and technical drawing)

- Building proportion, scale, texture, colour and - Model how it is composed

- Completeness of the model

- Detail of the model, proportion, scale, texture and colour

- The use of materials, finishing and detailing

The importance of each objective and task also has defined by percentage and level of satisfaction of jurors in each task was defined from fail, poor, average, good to excellent.

Four jurors were attending in submission day 4 jurors were attended one of them were $\mathrm{PhD}$ holder with more than 10 years experience, the other one was a senior lecturer with more than 15 years experience in practice and academics and two young lecturers with 3 years and 1 year experience respectively. Before starting the jury session, they had a meeting with master of the studio and discussed about the project and objectives in detail and each of the jurors received 23 evaluation form. Each student has given 10 to 15 minutes to explain his idea and the development process and planning details. After that jurors got time to ask questions and give comments. Finally the evaluation forms were collected from all jurors to be the base of total mark to students.

\subsection{Rasch Measurement Model and Mini Facet Software}

The development of Rasch Measurement Model in social science educational measurement has rapidly expanded to other areas of education including technical and engineering fields. And the problem can be solved with use of Rasch measurement model in architecture too. Rasch moves the concept of reliability from establishing 'best fit line' of the data into producing reliable repeatable measurement instrument (Azrila et al., 2008). This measurement model uses empirical data directly from the lecturer's assessment on student for a given task and transformed them into logic scale which have equal interval (Rashid et al., 2008).

Rasch analysis can be applied to assessments in a wide range of disciplines, including health studies, education, psychology, marketing, economics and social sciences. Rasch models are used for analyzing data from assessments to measure variables such as abilities, attitudes and personality traits. For example, they may be used to estimate a student's reading ability from answers to questions on a reading assessment. Rasch models are particularly used in psychometrics, the field concerned with the theory and technique of psychological and educational measurement.

Analyzing data according to the Rasch model, that is, conducting a Rasch analysis, gives a range of details for checking whether or not adding the scores is justified in the data. This is called the test of fit between the data and the model (Gulman and Mas'odi, 2009).

To evaluate the data from the studio we used Mini Facet software. The key in data has tabulated base on each student with different jury. So 1302 digit have had key in to the software.

\section{RESULTS AND DISCUSSION}

As Fig. 1 reveals, Teacher3 is the strictest assessor among the other teachers since Teacher 3 logit measure is at $3.17 \operatorname{logit}$. And the next logit measure is only at 1.39logit, a difference of $1.78 \log$ it.

Teacher4 is the most lenient among them all with logit at 0.96 measures. However further scrutiny, reveals that Teacher4 has Z-Std or high negative residual. Teacher4 under-rate easy criteria and over-rate on difficult criteria.

\begin{tabular}{|c|c|c|c|c|c|c|c|c|c|c|c|c|c|c|}
\hline Total & Total & Obsvd & Fair-MI & & Model | & Infit & & Outfi & & Estim.| & Corre] & lation | & Exact & Agree. | \\
\hline Score & Count & Average & Avrage $\mid \mathrm{M}$ & asure & S.E. & MnSq & ZStd & $\mathrm{MnSq}$ & ZStd | & Discrm| & PtMea & PtExp I & Obs : & Exp $q$ | N TEACHERS \\
\hline 134 & 56 & 2.4 & 1.991 & 3.17 & $.23 \mid$ & .84 & -.8 & .72 & $-1.3 \mid$ & $1.28 \mid$ & .80 & $.74 \mid$ & 43.8 & 34.9 | 3 teacher 3 \\
\hline 144 & 56 & 2.6 & 2.721 & 1.39 & $.23 \mid$ & 1.58 & 2.7 & 1.60 & 2.51 & $.36 \mid$ & .72 & $.79 \mid$ & 46.9 & $50.0 \mid 2$ teacher 2 \\
\hline 786 & 294 & 2.7 & 2.731 & 1.36 & .10 & 1.31 & 3.4 & 1.27 & 2.71 & $.64 \quad$ & .76 & .801 & 46.8 & 48.4 | 1 teacher 1 \\
\hline 784 & 280 & 2.8 & 2.851 & .96 & $.11 \mid$ & .51 & -6.9 & .53 & $-6.1 \mid$ & $1.46 \mid$ & .87 & .801 & 45.6 & 47.6 | 4 teacher 4 \\
\hline 462.0 & 171.5 & 2.6 & 2.571 & 1.72 & $.17 \mid$ & 1.06 & -.4 & 1.03 & $-.6 \mid$ & | & .79 & । & & | Mean (Count: 4) \\
\hline 323.0 & 115.6 & .1 & .341 & .85 & .061 & .41 & 4.1 & .42 & 3.6 & 1 & .06 & । & & I S.D. (Population) \\
\hline 373.0 & 133.5 & .2 & .391 & .98 & .071 & .47 & 4.8 & .49 & 4.2 & 1 & .06 & । & & | S.D. (Sample) \\
\hline
\end{tabular}

Fig. 1. Teachers measurement report 


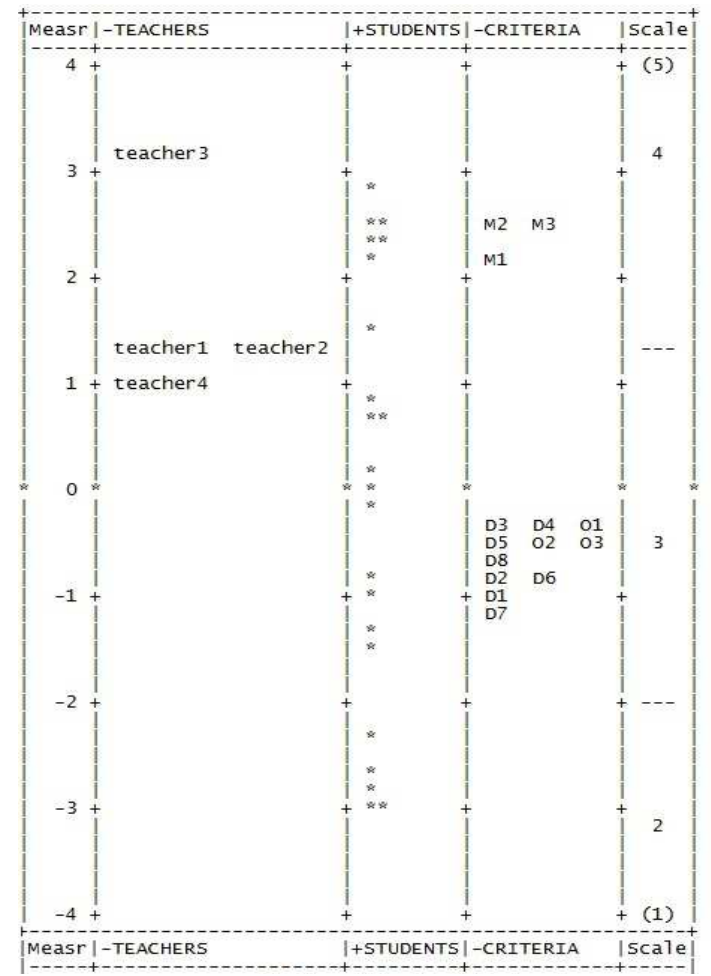

Fig. 2. All facet vertical rulers

Figure 2 shows the results of all facet vertical rulers. The first column includes measurement values which have calculated by the software. The next columns include teachers, students, criteria and scales, respectively.

Distributions of students in getting marks in different criteria by different teachers are shown by the star icons. It is observable that the measurement values of the teacher 1 , teacher 2 and teacher 4 are close to each other while the measurement value of the teacher 3 is more than other teachers.

Giving criteria in the brief would have an important influence on the form of questioning, but in tutors' and jurors' responses their first consideration was the strength and weakness of the students' design. The tutors and members of jury have their own preference and priorities and would tend to bias their questioning to accommodate these personal interests.

\subsection{Recommendations}

\subsection{Tutor Training Course}

Researches (Nicol and Pilling, 2000) has shown that in order to develop successful work-based learning, old prejudices must be set aside and new understanding and skills required. Instructors will need to be trained to understand and operate these programs, develop new teaching strategies and provide clear support documentation. Students need to be adequately supported in work-based learning. By developing learning contracts, students become independent learners and managers of their own educational process. This is the best way to create lifelong learners. One way which is implementing in some universities around the world is inducting inexperienced teacher by twinning in the unit with a more experienced teacher who, in an informal way, acted as a mentor. The new teacher then shared responsibility for the unit for at least a year, during which time he or she would experience the full round of the academic year, from the confusion of the introductory projects, through the doldrums of early spring, to fruition in the final portfolio. Only then would he or she go on to set up a new unit of his or her own. Such twinning can benefit the mentor as much as the mentee. It is a way of bringing new ideas into the school. Part time tutors have expressed their enthusiasm for and enjoyment of being part of the studio team and this has attracted some particularly bright and able young practitioners. They feel that working with a studio master across years is an 
invaluable experience and gives them good educational experience of many tutoring techniques. The other way is setting up workshops with aim of enabling practicing architects to become reflective studio teachers, able to define their educational aims, choose appropriate methods, implement a program and reflect on what has been achieved, with a view to refining their practice in the light of experience. Such workshops are holding in some British Universities like University of East London (UEL). In these workshops trainees attend one day a week for one year. In the first semester the trainees observe what is happening in the unit; the first obligation of the trainee, to observe, is not that easy. Trainees find it hard to hold back from action and only gradually recognize that it is an unusual privilege simply to be present. What happens in the studio will not be perfect and may sometimes be chaotic, but it is what students in the school are experiencing as their education. In the second they contribute under supervision to the teaching; and the third term they take more responsibility. At the end of the course they produce a proposal for a unit of their own. In many ways the course is modeled on the studio principle of the unit, with trainees and their teachers wrestling with the question" How should we teach architecture?" As in an architectural design, it involves a movement from analysis to proposition. Because of the many tacit elements in design studio teaching, this is not simple question of transmitting received wisdom. With the intention that trainees should have the opportunity to develop their own ideas about teaching on the basis of this experience the most fruitful educational problems are open-ended and teachers do not know all the answers. The program relies heavily on experiential learning. In the first semester each trainee presents one study reflecting on his or her own education and another on some significant event he or she has observed in the students' experience in the unit. During the second term the focus is on contextualising the teaching of architecture within current models of professional knowledge and theories of learning in higher education: the trainees write a study discussing a particular text and a second paper reflecting on students' experience of crits and reviews. As teachers frequently hold on to the old teaching ways, the proven methods and the tested techniques and yet if they do not adopt both in terms of course content and teaching, it is likely that graduates will not acquire the range of skills required of today's professionals, whilst academic staff will wear themselves out using old techniques in new situations. In these workshops each individual tutor will bring her or his own personality and flavor to the student's learning experience through the studio. Important to achieving parity whilst maintaining variety id the recent development of clear guidelines on assessment criteria being made available to the students, as well as written feedback on reviews. Tutors are becoming more confident about developing their own new methods for studio teaching. There is more discussion about studio teaching methods and two studios often join together to develop new methods. At the weekly lunches, studio masters who are less successful have perceived the need to change and are generally supported and helped by more confident colleagues.

\section{CONCLUSION}

Learning form faults at the job in terms of gaining experience is completely acceptable and is a positive part of each project but in case of education would be a concern. Since it is the nature of artistic fields like architecture and each project is unique to itself and each student and his background, talent is unique to itself so the master of the studio needs to be prepared for this sophisticated challenge before entering to the class and also need support in further steps and years. Young tutors and Part time instructors would express enthusiasm and enjoyment of being part of the studio team and this has attracted some particularly bright and able young practitioners. Part time tutors may feel that working with a studio master across years is an invaluable experience that gives them good educational experience of many tutoring techniques.

The skills which are required to teach successfully cannot be acquired in the context of practice. Teaching is a separate order of things, tied to practice certainly, but by analogy, not by stricture.

It may be that some colleagues in architecture fear that any form of training might stifle the creative spirit of design tutoring, leading to mediocrity and uniformity.

Exchange of idea and experience among senior lecturers and the tutors with more practical lectures can produce fertile base to improve architecture education and having more creative education in architecture filed. In this way teaching can, of course, be a very effective kind of learning. Taking different roles produces different learning.

\section{REFERENCES}

Astin, A.W., 1992. Principles of Good Practice for Assessing Student Learning. 1st Edn., American Association for Higher Education, Washington, DC., pp: 8. 
Azrila, A.A., A. Mohamed, N.H. Arshad, S. Zaharim and H.A. Ghulman et al., 2008. Application of Rasch model in validating the construct of measurement instrument. Int. J. Educ. Inform. Technol., 2: 105-112.

Boyer, E.L. and L.D. Mitgang, 1996. Building Community: A New Future for Architecture Education and Practice: A Special Report. 1st Edn., Carnegie Foundation for the Advancement of Teaching, Princeton, NJ., pp: 172.

Brown, R. and D.M. Yates, 2002. Environmentbehaviour studies and its absent place in architectural education. University of East London.

Crooks, T.J., M.T. Kane and A.S. Cohen, 1996. Threats to the valid use of assessments. Assessment Educ.: Principles, Policy Practice, 3: 265-286. DOI: 10.1080/0969594960030302

Gulman, H.A. and M.S. Mas'odi, 2009. Modern measurement paradigm in Engineering Education: Easier to read and better analysis using Rasch-based approach. Proceedings of the 2009 International Conference on Engineering Education, Dec. 7-8, IEEE Xplore Press, Kuala Lumpur, Malaysia, pp: 16. DOI: 10.1109/ICEED.2009.5490624

Mahmood, A., 2008. Attitudes towards help-seeking among south asian american muslim women. 1st Edn., ProQuest, ISBN-10: 1109023804, pp: 158.

Nicol, D. and S. Pilling, 2000. Changing Architectural Education: Towards a New Professionalism. 1st Edn., Taylor and Francis, London, ISBN-10: 0419259201, pp: 320.
O'Reilly, D., N. Weaver and M. Caddick, 1999. Developing and delivering a tutor training programme for problem based learning: A case study in architecture. University of Newcastle.

Pearce, M. and M. Toy, 1995. Educating Architects. 1st Edn., Academy Editions, London, ISBN-10: 1854903918, pp: 128.

Polanyi, M., 1967. The Tacit Dimension. 1st Edn., Routledge and Kegan Paul, London, pp: 108.

Rashid, R.A., R. Abdullah, H.A. Ghulman and M.S. Masodi, 2008. Application of Rasch-based ESPEGS model in measuring generic skills of engineering students: A new paradigm. WSEAS Trans. Adv. Eng. Educ., 5: 591-602.

Rhowbotham, K., 1995. Form to Programme. 1st Edn., Black Dog Publishing, London, ISBN-10: $095217734 \mathrm{X}$, pp: 65.

Sadler, D.R., 2005. Interpretations of criteria-based assessment and grading in higher education. Assessment Eval. Higher Educ., 30: 175-194. DOI: 10.1080/0260293042000264262

Schon, D.A., 1985. The Design Studio: An Exploration of Its Traditions and Potentials. 1st Edn., RIBA Publications for RIBA Building Industry Trust, London, ISBN-10: 0947877452, pp: 99.

Schon, D.A., 1990. Educating the Reflective Practitioner: Toward a New Design for Teaching and Learning in the Professions. 1st Edn., Jossey-Bass Inc., San Francisco, CA., ISBN-10: 1555422209, pp: 376. 